\title{
UCRL-TR-223365
}

LAWRENCE LIVERMORE N A TIO N A L LABORATORY
ALE3D Rolling Simulations

T.E. Riordan

August 3, 2006 
This document was prepared as an account of work sponsored by an agency of the United States Government. Neither the United States Government nor the University of California nor any of their employees, makes any warranty, express or implied, or assumes any legal liability or responsibility for the accuracy, completeness, or usefulness of any information, apparatus, product, or process disclosed, or represents that its use would not infringe privately owned rights. Reference herein to any specific commercial product, process, or service by trade name, trademark, manufacturer, or otherwise, does not necessarily constitute or imply its endorsement, recommendation, or favoring by the United States Government or the University of California. The views and opinions of authors expressed herein do not necessarily state or reflect those of the United States Government or the University of California, and shall not be used for advertising or product endorsement purposes.

This work was performed under the auspices of the U.S. Department of Energy by University of California, Lawrence Livermore National Laboratory under Contract W-7405-Eng-48. 


\section{ALE3D Rolling Simulations}

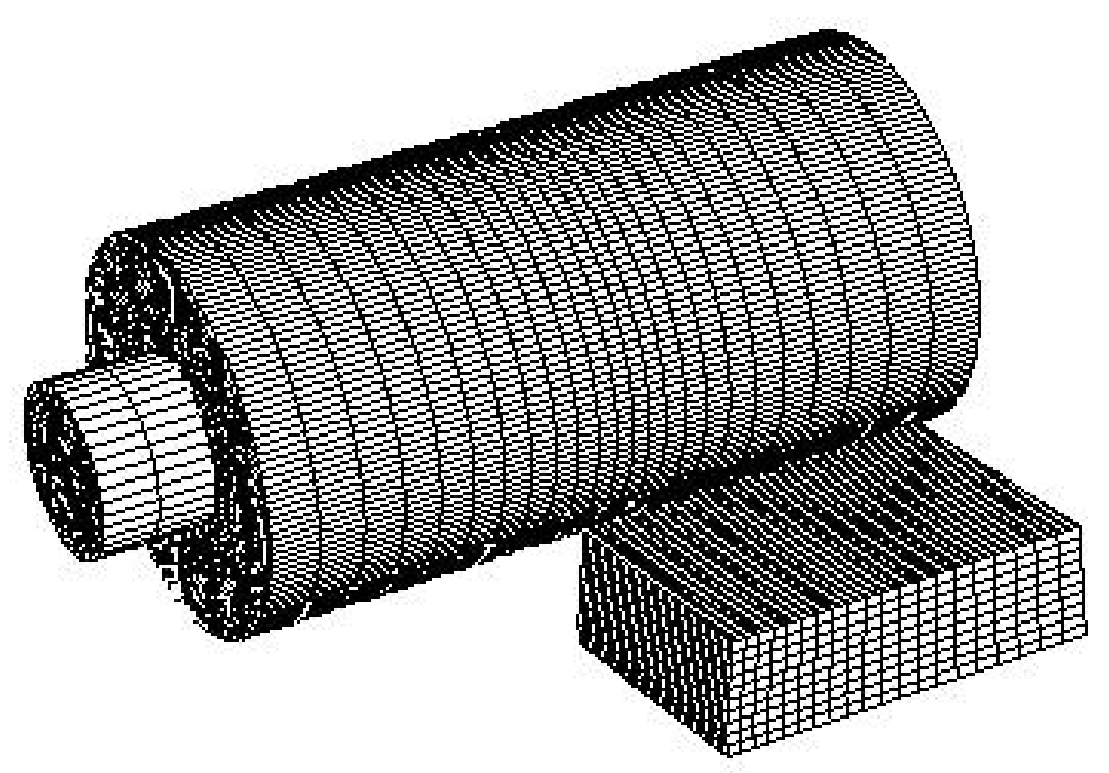

Tom Riordan

July 27, 2006 


\section{Executive Summary}

Hot rolling is a problem involving large deformations during the process of turning an ingot into a thin sheet. As a result of the large deformations inherent in the process, significant amounts of energy are put into the ingot mechanically, most of which results in heat generation. Therefore, in order to predict the results of rolling both the mechanical and the thermal factors must accurately represent the real conditions. The factors which must be properly tuned include interface friction, mass scaling to decrease computation times, heat transfer at the interface, convective heat transfer from the ingot, and convective heat transfer from the roll. Since these parameters are generally not measurable the correct values must be derived by tuning the parameters so that solutions match some other measurable result.

The interface friction will be tuned using an ALE3D input deck which has been set up to output the torque applied to the roll during the pass. The friction coefficient will be adjusted so that the computed torque matches the measured value.

The various heat transfer coefficients are dependent on each other, and are tuned based on measured roll surface temperatures, ingot exit temperatures, and the energy input through the mechanical deformation of the ingot. The heat transfer coefficient at the interface has been found to be approximately $1.25 \times 10^{5} \mathrm{~W} / \mathrm{m}^{2} \mathrm{~K}$, based on estimates of how much heat can be taken from the roll surface by coolant and matching a roll surface temperature. The convection coefficient on the ingot surface has been assumed to be $100 \mathrm{~W} / \mathrm{m}^{2} \mathrm{~K}$, on the high end for convection to air. However, this convection coefficient is low enough that the ingot should cool uniformly through its thickness as it would with a lower convection coefficient.

Also necessary in accurate modeling is a good description of material behavior. In order to aid the development of an accurate material model an ALE3D input deck which simulates compression tests with temperature gradients has been developed. The model output engineering stress-strain curves which can be compared to the experimentally collected data. Also, comparisons of the deformed shapes can be made. The model has been tuned using MTS parameters for AA 5182 and will be ready for use when parameters for AA 2024 are experimentally developed.

Currently, more work is needed to properly tune all the model parameters. A parameterized three dimensional geometry and mesh has been created so that once the parameters are tuned the transition to three dimensional simulations should be quick.

\section{Introduction}

In order to model aluminum hot rolling, many thermal and mechanical parameters must be tuned to give accurate results. As full three dimensional models are expensive and time consuming the best way to tune these parameters and learn to apply the proper boundary conditions is through smaller, usually two dimensional, problems. These problems are set up so that only one parameter is being varied at a time so that its effects on the solution can be seen. The parameters are then tuned so that they produce a result that matches with some measurable quantity, for instance, a temperature measured at some location. Parameters fall into the two main categories of mechanical or thermal. The parameters being tuned included interface friction, interface heat transfer, convection from the ingot, and convection from the roll. Also, to decrease solution time it is desirable to use larger time steps while still maintaining stability, 
which is done by using mass scaling. The mass scaling must be tuned so that the time step is as large as possible without inertial effects significantly changing the solution.

Since hot rolling involves significant plastic deformation, in order to produce useful results it is necessary to describe the material response. Generally, this is done by performing material tests and fitting equations to the data to create a mathematical model of the material response. This model can then be used in the simulation to describe the response. However, before using the model for the actual simulation, it is desirable to verify that it accurately describes the material response. This verification is accomplished through running simulations of the tests used to develop the model and then comparing both deformed shapes and load displacement curves output by the simulation to those of the tests.

Once the parameters have been tuned to give satisfactory results and the material model is verified, all of these parts can be brought together to perform three dimensional simulations.

\section{Mechanical}

\section{$\underline{\text { Mechanical Boundary Conditions }}$}

The first step in the mechanical portion of the problem was learning to apply the initial conditions and boundary conditions on a two dimensional rolling problem. The steps are outlined below:

1. Apply an initial velocity to the ingot and an initial angular velocity to the roll.

2. Drive the roll by applying a constant angular velocity to the spindle portion of the roll.

3. Once the ingot has completed its pass through the mill, remove the constant angular velocity boundary condition from the spindle.

4. Set the velocities of the entire roll and the entire ingot to zero, so that the mass scaling can be increased during the thermal only portion of the process.

5. After waiting a typical interpass time, decrease the mass scaling and lower the roll (or raise the ingot) into position for the next pass.

6. Apply the in the initial conditions from step one with opposite signs, and repeat the above process.

\section{$\underline{\text { Roll Torque Calculation }}$}

An important parameter in the rolling problem is the friction at the interface between the roll and the ingot. Since a friction coefficient cannot be measured directly, it must be tuned based on other measurable parameters. The roll torque is one parameter that is both measurable and effected by the friction coefficient. In order to tune the friction coefficient based on the roll torque, the ALE3D input deck needed to be set up to measure the torque applied to the roll through time. In order to facilitate the use of ALE3D derived variables, the rolling problem was set up so that the roll is always centered at the xy origin, which means that the radius vector, $r$, of any node is given directly by its xy-coordinates, or

$$
r=x \hat{i}+y \hat{j}
$$


Since a constant angular velocity boundary condition is applied to the nodes of the spindle there are corresponding reaction forces on these nodes given by

$$
f=f_{X} \hat{i}+f_{Y} \hat{j}
$$

From these, the portion of the torque applied to each individual node, $\mathrm{T}_{\mathrm{i}}$, can be found by the cross product of the radius and force, or

$$
T_{i}=r \times f=x f_{Y}-y f_{X}
$$

The total torque, $\mathrm{T}$, applied to the roll is then given by

$$
T=\sum_{i=1}^{\# \text { nodes }} T_{i}
$$

In order to verify that the calculation produced the correct output, a simple limit load problem was set up using an elastic perfectly plastic material. In this problem the outside surface of the roll was held fixed and the constant angular velocity was applied to the inside surface. The torque should increase steadily until the material yields, at which point it should stay constant at a value of

$$
T=r A \tau
$$

where $\tau$ is the magnitude of the shear stresses and A is the surface area over which the boundary conditions are applied. Since a Von Mises yield criterion was used $\tau$ can be determined from

$$
\sigma_{\text {eff }}=\sigma_{Y}=\sqrt{\frac{3}{2} \sigma_{\sim}^{\prime}: \sigma_{\sim}^{\prime}}=\sqrt{3 \tau^{2}}
$$

where $\sigma_{\text {eff }}$ is the effective stress, $\sigma_{\mathrm{Y}}$ is the yield stress, and $\sigma^{\prime}$ is the deviatoric stress tensor. Figure 1 shows the roll before the constant angular velocity has been applied and Figure 2 shows the shear stresses in the elements after yielding. The plot of torque versus time shown in Figure 3 clearly shows the desired limit load behavior.

Once the accuracy of the torque calculation had been verified the next step was to run a two dimensional simulation and output the torque. The desired result is that the torque should rise up steadily as the ingot enters, reach a steady state value, and then steadily decrease to zero as the ingot leaves the mill. A screenshot of the simulation during a steady torque time period can be seen in Figure 4. The $\mathrm{x}$ and $\mathrm{y}$ direction forces which the torque was derived from are plotted in Figures 5 and 6, respectively. The behavior of the torque can be seen in Figure 7, a plot of the torque versus time in the two dimensional rolling simulation. The plot also shows periodic noise, so a second simulation was run with the element size cut in half to attenuate the noise. The torque versus time curve for the second simulation is shown in Figure 8. For a time period when the torque was relatively constant between 0.4 and 0.5 seconds the first simulation (element edge length $\sim 0.046 \mathrm{~m}$ ) had an average value of $123,957 \mathrm{~N}-\mathrm{m}$ and a standard deviation 
of $8,185 \mathrm{~N}-\mathrm{m}$. The second simulation (element edge length $\sim 0.023 \mathrm{~m}$ ) with the mesh size halved resulted in an average value of $125,829 \mathrm{~N}-\mathrm{m}$ with a standard deviation of $6,538 \mathrm{~N}-\mathrm{m}$.

\section{Mass Scaling}

The stability of the equations used in ALE3D's finite element formulation is based on the Courant Limit given by

$$
\Delta t \leq \sqrt{\frac{\rho(\Delta x)^{2}}{K}}
$$

where $\Delta t$ is the time step, $\rho$ is the density, $\Delta x$ is the characteristic element length, and $K$ is the bulk modulus of the material. In order to increase the size of the time step allowed, ALE3D allows the user to scale the time step up by scaling the mass. In order to accomplish this, the mass is scaled by the square of the requested time step scaling factor. In dynamic problems this increase in mass can lead to inertial effects which are not actually present in the physical situation. Ideally, the time steps used would be as large as possible without having a significant effect on the solution. In order to determine what level of mass scaling can be used while still resulting in an acceptable, solution two dimensional simulations were run with various values of mass scaling. Results of these simulations for variables such as plastic strain rate were compared to the base case of no mass scaling. The solutions were also qualitatively inspected for plastic strain rate in places that should not be plastically straining. Through this analysis it was determined that beyond a level of scaling time by a factor of 5 (mass by 25) the solutions started to degrade.

\section{Thermal}

\section{Deformation Heat Generation}

In rolling, large amounts of energy are put into the ingot in order to deform it. The majority of this deformation energy manifests itself in the form of heat. A first approximation of the deformation energy can be made using the following process. First, the horizontal contact length, $\Delta \mathrm{x}$, is determined using

$$
\Delta x=\sqrt{r^{2}-\left(r-\frac{D}{2}\right)^{2}}=r \sqrt{\frac{D}{r}-\left(\frac{D}{2 r}\right)^{2}}
$$

where $\mathrm{r}$ is the roll radius and $\mathrm{D}$ is the draft, shown in Figure 9. The roll radius is $0.43815 \mathrm{~m}$ and the draft for the first pass is $0.03048 \mathrm{~m}$ resulting in a horizontal contact length of $0.1146 \mathrm{~m}$. The time that the ingot is in the roll bite, $\Delta \mathrm{t}$, is then given by 


$$
\Delta t=\frac{\Delta x}{r \omega}
$$

where $\omega$ is the angular velocity of the roll, which is $2.609 \mathrm{rad} / \mathrm{s}$, resulting in a contact time of approximately $0.1 \mathrm{~s}$. The average strain rate through the thickness of the material can then by approximated by

$$
\dot{\varepsilon}=\frac{D / H}{\Delta t}
$$

where $\mathrm{H}$ is the initial thickness $(0.51054 \mathrm{~m})$ of the ingot defined in Figure 9. This results in an average strain rate of approximately $0.61 / \mathrm{s}$. The average stress through the thickness of the material was then found using the hyperbolic sine model given by

$$
\begin{aligned}
& \sigma=\frac{1}{\beta} \operatorname{Sinh}^{-1}\left[\left[\frac{Z}{A}\right]^{\frac{1}{N}}\right] \\
& \text { where } Z=\dot{\varepsilon} \exp (H / R T) \quad \beta=0.02835 / \mathrm{MPa} \\
& A=2.397 \times 10^{10} / \mathrm{sec} \quad H=283200 \mathrm{~J} / \mathrm{mole} \\
& N=2.83 \quad R=8.314 \mathrm{~J} / \mathrm{mole} / \mathrm{K}
\end{aligned}
$$

where $\mathrm{T}$ is the temperature of the ingot. Using the lay-on temperature of $758 \mathrm{~K}$, we find an average stress of approximately $280 \mathrm{MPa}$. From the stress and the strain rate a volumetric deformation energy rate, $\mathrm{Q}$, can be determined from

$$
Q=\sigma \dot{\varepsilon}
$$

which results in a volumetric deformation energy rate of $1.67 \times 10^{8} \mathrm{~W} / \mathrm{m}^{3}$. The volumetric deformation energy rate will be applied to the entire volume of the ingot such that the total deformation energy rate, $q$, will be given by

$$
q=Q V
$$

where $\mathrm{V}$ is the volume of the ingot. The ingot has a volume of approximately $6.12 \mathrm{~m}^{3}$, which results in at total deformation energy rate of $1.022 \mathrm{GW}$. In order to maintain the approximately constant temperature of the ingot all of this energy must be removed through either heat transfer to the roll or heat transfer to the ambient, such that

$$
q \Delta t=q_{\text {amb }} t_{\text {cool }}+q_{\text {roll }} t_{\text {pass }}
$$

where $\mathrm{q}_{\mathrm{amb}}$ is the heat transferred to the ambient, $\mathrm{t}_{\text {cool }}$ is the cooling time, $\mathrm{q}_{\text {roll }}$ is the heat transferred into the roll, and $t_{\text {pass }}$ is the entire time for the pass. The heat transferred to the roll is given by 


$$
q_{\text {roll }}=h_{\text {surf }} A_{C}\left(T_{\text {ingot }}-T_{\text {roll }}\right)
$$

where $h_{\text {surf }}$ is a heat transfer coefficient representing the gap conductance at the roll-ingot interface, $A_{C}$ is the interface contact area, $T_{\text {ingot }}$ is the surface temperature of the ingot, and $T_{\text {roll }}$ is the surface temperature of the roll. During the process the average surface temperature of the roll remains constant, which means that all of the heat transferred into the roll from the ingot must be removed the coolant spray, such that

$$
q_{\text {roll }}=h_{\text {surf }} A_{C}\left(T_{\text {ingot }}-T_{\text {roll }}\right)=h_{\text {cool }} A_{S}\left(T_{\text {roll }}-T_{\text {cool }}\right)
$$

where $\mathrm{h}_{\text {cool }}$ is the convection coefficient of the coolant, $\mathrm{A}_{\mathrm{S}}$ is the surface area hit by the spray, and $\mathrm{T}_{\text {cool }}$ is the temperature of the coolant. The heat transferred to the ambient is given by

$$
q_{\text {amb }}=h_{\text {amb }} A_{\text {ingot }}\left(T_{\text {ingot }}-T_{\text {amb }}\right)
$$

where $h_{\text {amb }}$ is the convection coefficient of the ambient, $A_{\text {ingot }}$ is the surface area of the ingot, and $\mathrm{T}_{\mathrm{amb}}$ is the ambient temperature. Any heat which was not transferred into the roll must then be transferred to the ambient. Assuming a generous convection coefficient $h_{a m b}$ of $100 \mathrm{~W} / \mathrm{m}^{2} \mathrm{~K}$ we can make an estimate of the time that the ingot must be allow to cool. The Biot number of the ingot, given by

$$
B i=\frac{h_{a m b} L}{k}=\frac{h_{a m b} V}{k A_{\text {ingot }}}
$$

where $\mathrm{k}$ is the thermal conductivity of $273 \mathrm{~W} / \mathrm{mK}$, is approximately 0.09 for the first pass and decreasing in each successive pass as the surface area increases. Since the Biot number is small lumped mass capacitance can be assumed. Making this assumption the cooling rate of the ingot can be estimated by

$$
\frac{d T}{d t}=\frac{h_{a m b} A_{\text {ingot }}\left(T_{\text {ingot }}-T_{\text {amb }}\right)}{\rho V C_{p}}
$$

where $\mathrm{C}_{\mathrm{p}}$ is the specific heat. For the first pass this cooling rate turns out to be approximately $0.08 \mathrm{~K} / \mathrm{s}$. Energy is transferred to the roll almost instantaneously, so that portion of the deformation energy will have little effect on the average ingot temperature. Based on this assumption the average temperature increase can be estimated by

$$
\Delta T=\frac{q_{\text {amb }} t_{\text {cool }}}{\rho V C_{p}}=\frac{q \Delta t-q_{\text {roll }} t_{\text {pass }}}{\rho V C_{p}}
$$




\section{$\underline{\text { Roll Temperature Distribution }}$}

In order to heat up the roll to its operating temperature, several ingots which are later scrapped get passed through the mill. The computation costs of simulating this would be very high; therefore, a different approach has been devised to allow the roll to reach its equilibrium temperature distribution. The approach entails simulating the heat transfer from the ingot to the roll as a fixed heat flux at the contact area.

To make the mechanical portion of the problem unconditionally stable, every node on the roll will be given the constant angular velocity boundary condition. This allows the use of large fixed time steps several orders of magnitude greater than those that can be taken during the simulation of rolling. The time steps in this problem are limited only by the requirement that the applied heat flux cannot "miss" nodes as the roll rotates.

In order to tune the convection coefficient of the coolant, $\mathrm{h}_{\text {cool }}$, the problem was first done in two dimensions simulating a slice of the roll around the middle of the roll-ingot contact width, where it could be assumed that axial conduction through the roll would be negligible. The boundary conditions of this problem are shown in Figure 10. It was assumed that no heat flux came out of either face of the cylinder (i.e., no axial heat conduction). The convection coefficient of $10,500 \mathrm{~W} / \mathrm{m}^{2} \mathrm{~K}$ was adjusted so that element centered temperature of the surface elements approximately oscillated around the average roll surface temperature of 477.4 Kelvin. Figure 11 shows a plot of a surface element's temperature oscillations. The specified heat flux value of $34.844 \times 10^{6} \mathrm{~W} / \mathrm{m}^{2}$ represents an $\mathrm{h}_{\text {surf }}$ value of $1.24 \times 10^{5} \mathrm{~W} / \mathrm{m}^{2} \mathrm{~K}$ applied to the $15^{\circ}$ contact arc.

Once the convection coefficients were tuned in the two dimensional problem, the heating technique was then tested on a three dimensional roll. The part of the roll which will be in contact with the ingot starts off at the measured operating temperature of 477.4 Kelvin. To simulate passing the ingots under the roll, the roll will be rotated at a constant angular velocity and the heat flux representing $\mathrm{q}_{\mathrm{roll}}$ will be applied at the contact area. The convection coefficient of the coolant, $\mathrm{h}_{\text {cool }}$, will be applied to this portion of the surface. The portion of the roll which is outside of the contact region will be given a linear temperature distribution starting at 477.4 Kelvin where it meets the hot end, down to an ambient temperature at the far end. A convection coefficient of $100 \mathrm{~W} / \mathrm{m}^{2} \mathrm{~K}$ representing ambient will be applied to this portion of the surface. Since the convection coefficient in this portion is not very large we can surmise that the radial temperature gradients through most of the cylinder will be small, and therefore the linear distribution in the axial direction should be close to the equilibrium solution. These boundary conditions and initial conditions are displayed in Figure 12. A plot of the nodal temperature distribution after 200 seconds ( 83 revolutions) is shown in Figure 13. This temperature profile will be used as the initial conditions for the rolling simulations.

\section{Material Model Validation}

In order to develop a Mechanical Threshold Stress (MTS) model of AA 2024, compression tests are being performed on cylindrical specimens with linear temperature gradients in the axial direction. An ALE3D model is being developed to validate the model parameters found in these tests. This model consists of the cylindrical specimen modeled using quarter symmetry and two platens. The model will be equipped to output engineering stress- 
strain curves that can be compared with the experimental data. Also, the deformed shapes of the physical specimens and the model will be compared.

The problem will first be solved implicitly using reduced integration elements. Since friction is not currently supported in ALE3D's implicit hydrodynamics, the simulation will then be run explicitly to so that friction can be taken into account. The explicit simulation will first be run with friction turned off so that mass scaling and hourglass controls can be adjusted give a solution that matches the baseline implicit solution. Once the mass scaling and hourglass controls have been properly adjusted friction will be turned on so that its effects can be seen.

While the MTS parameters for AA 2024 are being developed, the ALE3D input deck is being tuned using the MTS parameters for AA 5182 (see Table 1) given by Bange et al. [1]. The simulation begins with the upper and lower platens held at fixed temperatures of $633 \mathrm{~K}$ and 485 $\mathrm{K}$, respectively. The initial temperature of the compression specimen is the average of the upper and lower platens, $559 \mathrm{~K}$. The contact heat transfer coefficient, $\mathrm{k}_{\text {gap }}$, is set so that the resulting temperature distribution will match the experimentally calculated values. Before any compression takes place the specimen is allowed to reach its steady state linear temperature distribution, which is shown in Figure 14. Upon reaching the steady state temperature distribution the upper platen is given a downward velocity in order to compress the specimen at the desired strain rate, $1 / \mathrm{s}$ in this case. The simulation is stopped when the specimen reaches $50 \%$ of its original length. The distribution of plastic strain at the end of the simulation for both the implicit and explicit solutions are shown in Figures 15 and 16, respectively. The engineering stress strain curves from both the implicit and explicit solution are shown in Figure 17. As seen in the plots the curves are approximately the same in both cases, with the explicit solution displaying more noise and a small spike at the start.

\section{Three Dimensional Simulation}

The different pieces discussed in the preceding sections will be put together to run three dimensional simulations. The transition from running two dimensional rolling simulations to three dimensional simulations should be relatively smooth, as it should on require slight modifications to the two dimensional ALE3D input deck. To keep computational cost down the three dimensional model will take advantage of the symmetry present in the problem by using the symmetry planes shown in Figure 18. The problem geometry and mesh have been created using the meshing software Truegrid. The Truegrid input file is parameterized to simplify the process of modifying the mesh.

\section{Conclusion}

Through this work, progress has been made towards being able to run accurate three dimensional simulations. A better understanding of both the mechanical and thermal boundary conditions affecting the solution has been gained. Simple methods for tuning these boundary conditions have been developed and will be useful when future changes to these boundary conditions need to be made. Also, a model has been created that will help to validate the material model which will give more confidence in the solutions garnered by the full three 
dimensional simulations. More work is still required to properly tune the model parameters, but the tools necessary to do so are now available.

\section{References}

[1] Bange, M.E., Beaudoin, A.J., Stout, M., Chen, S.R., MacEwen, S.R., 2000, "Predictive Modeling of the Nonuniform Deformation of the Aluminum Alloy 5182," Journal of

Engineering Materials and Technology, Vol. 122, pp. 149-156 


\section{Appendix - Figures and Tables}

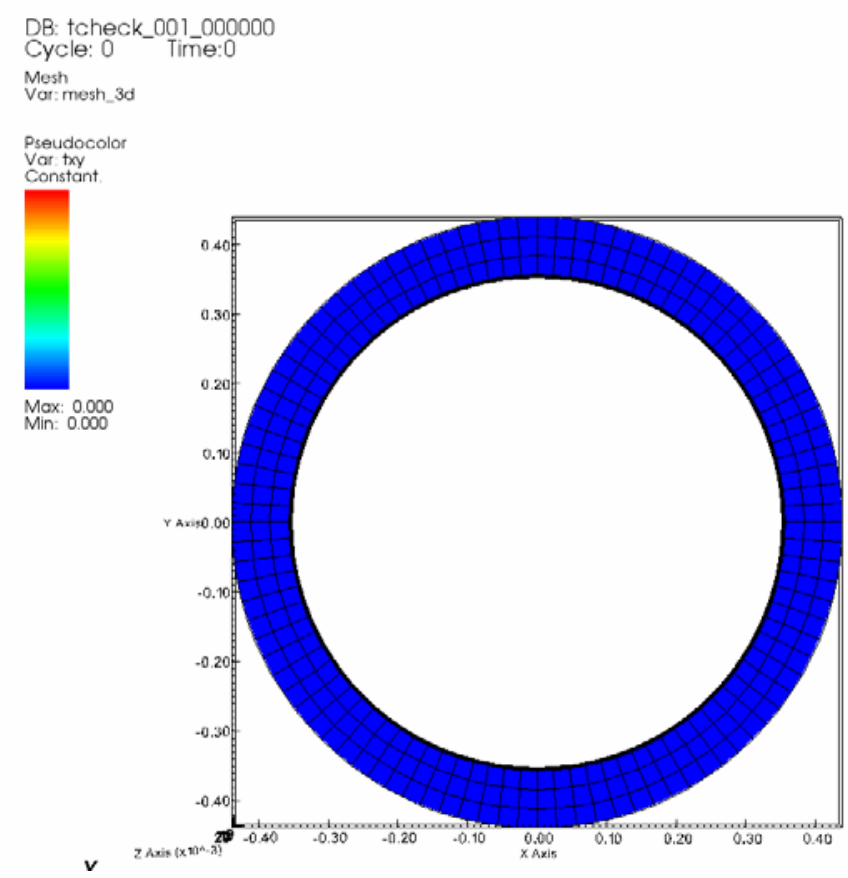

Figure 1. Limit load torque check before torque is applied to the inner surface.

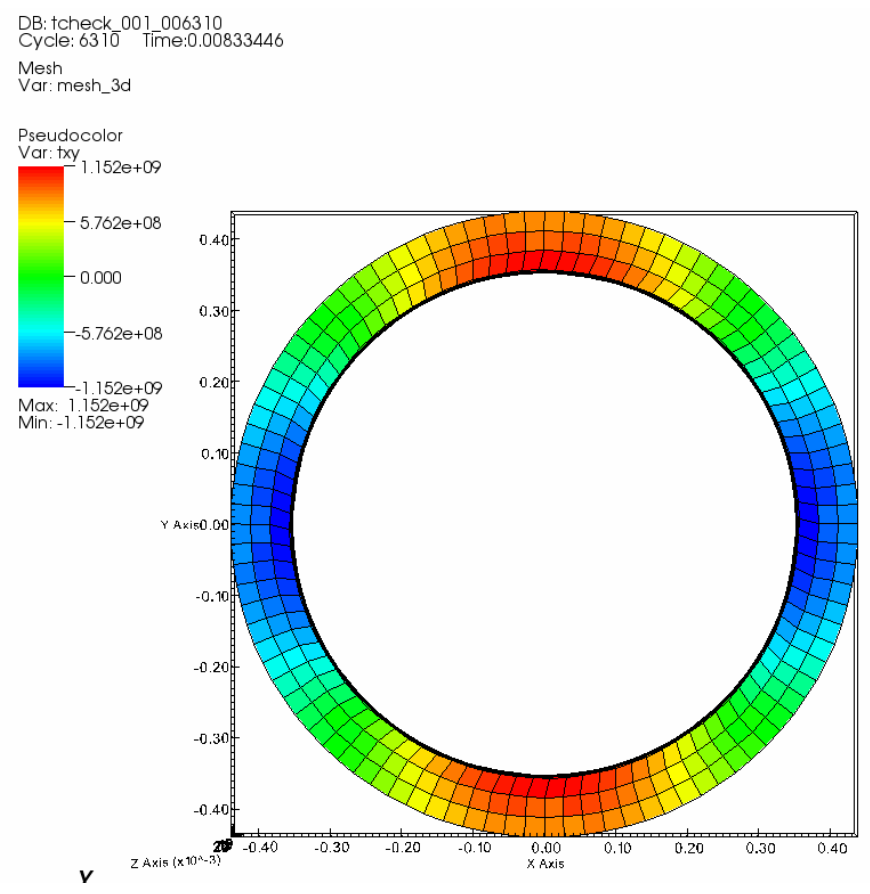

Figure 2. Shear stress in the roll after torque has been applied to the inner surface. 


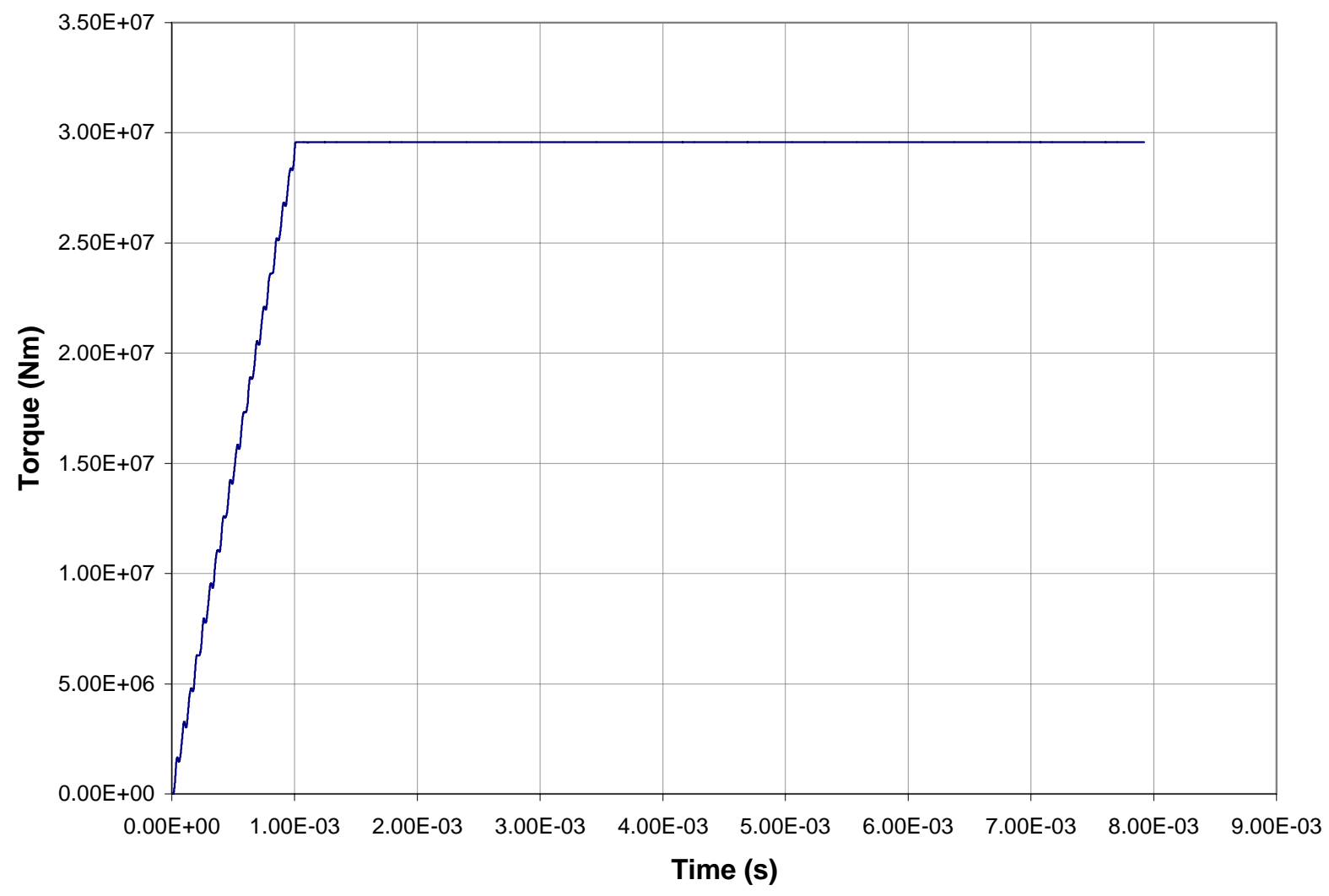

Figure 3. Torque vs. time in limit load problem

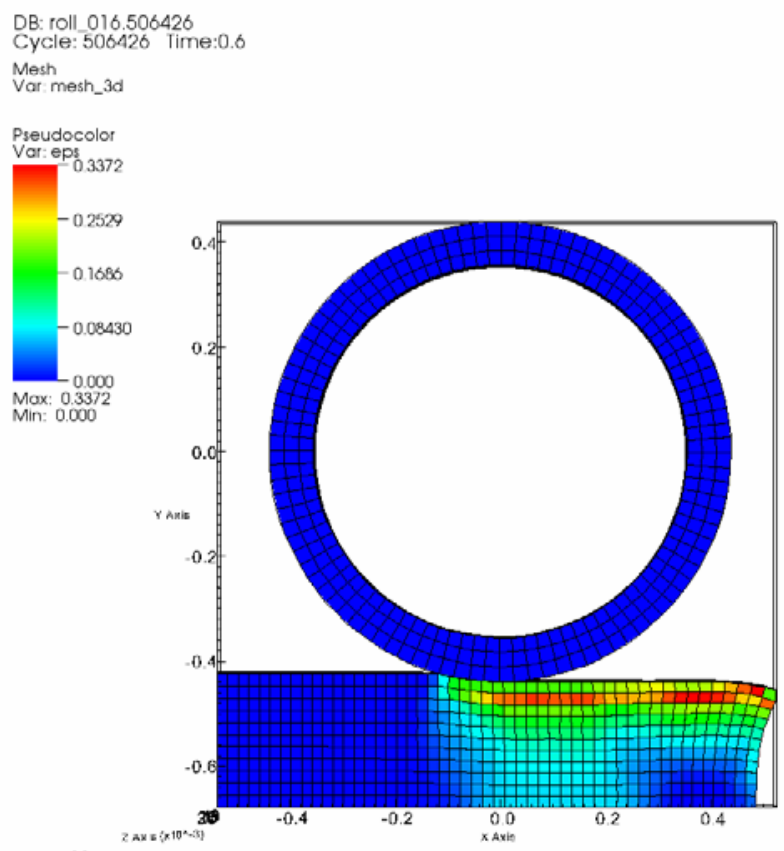

Figure 4. Rolling simulation during mid pass 


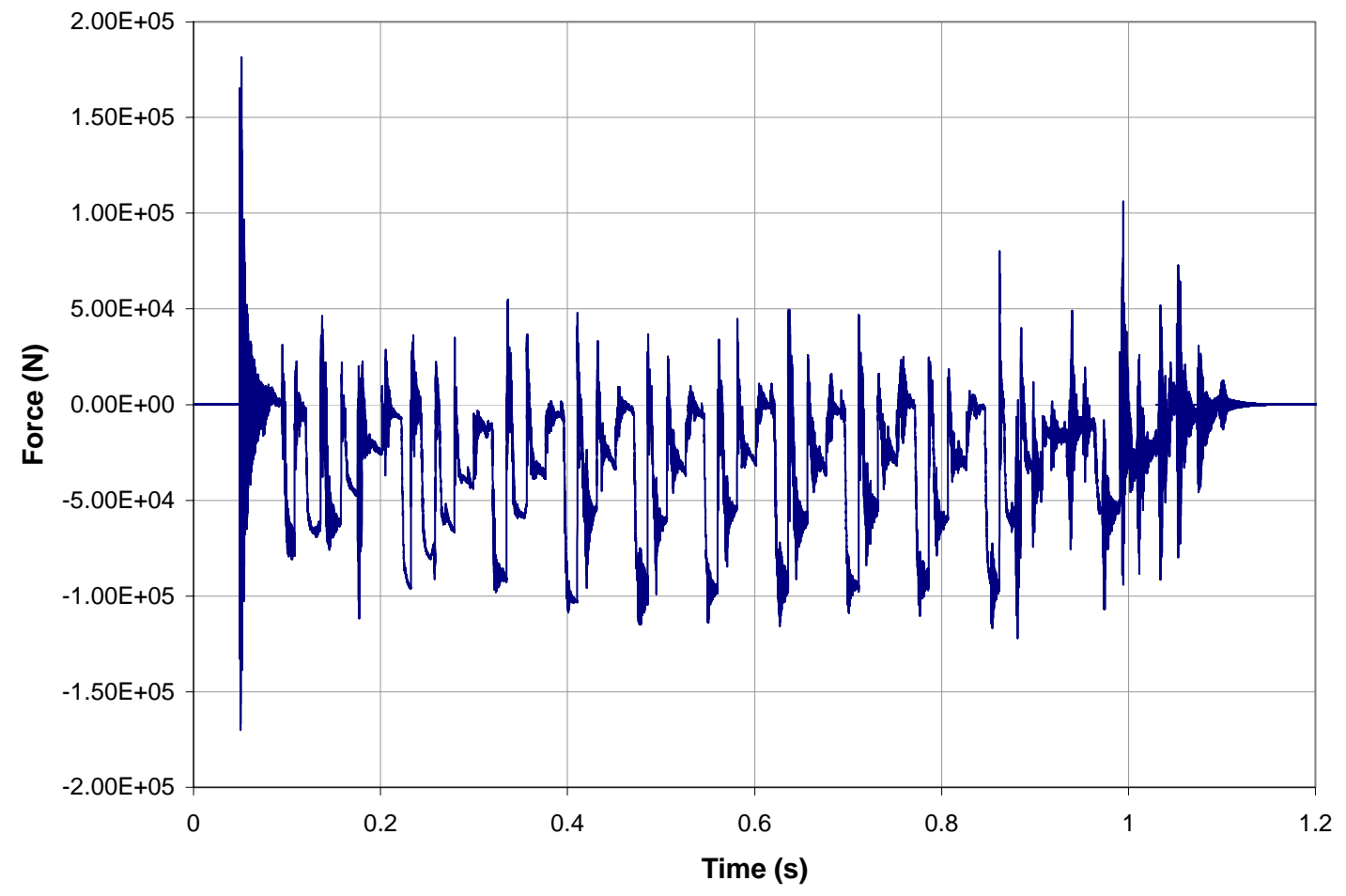

Figure 5. Forces in the x-direction.

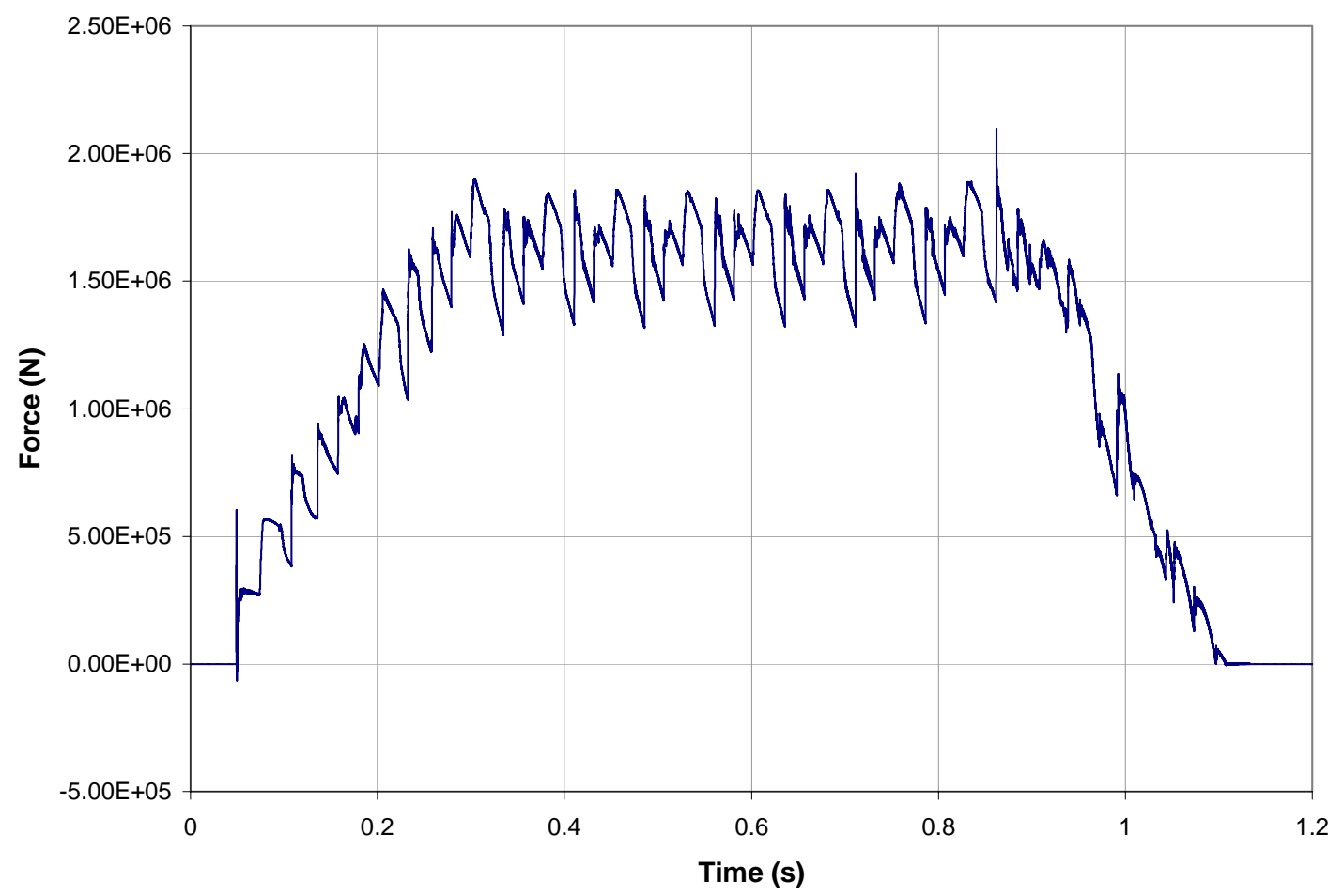

Figure 6. Forces in the y-direction. 


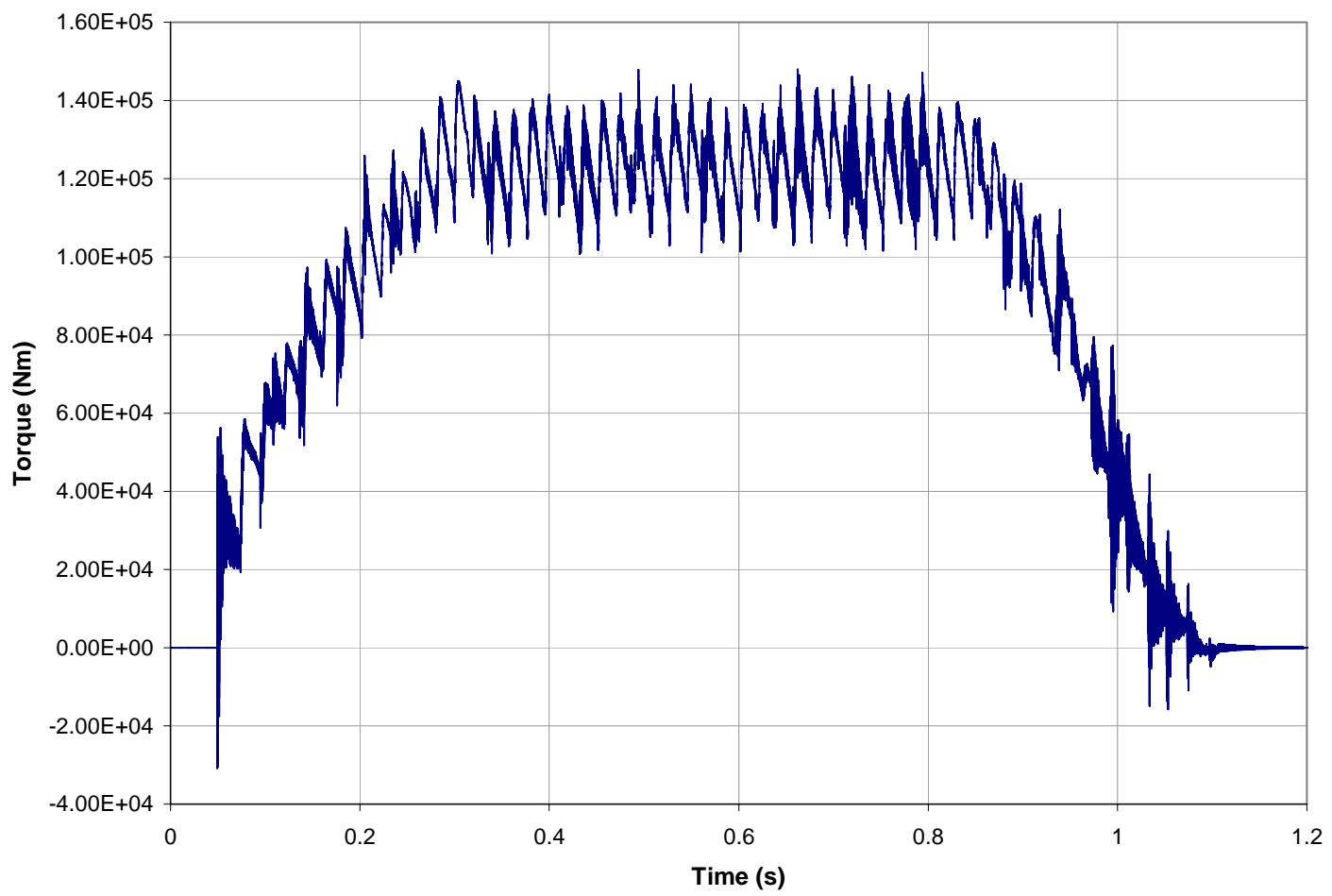

Figure 7. Torque vs. time in first rolling simulation (element size $\sim 0.046 \mathrm{~m}$ ).

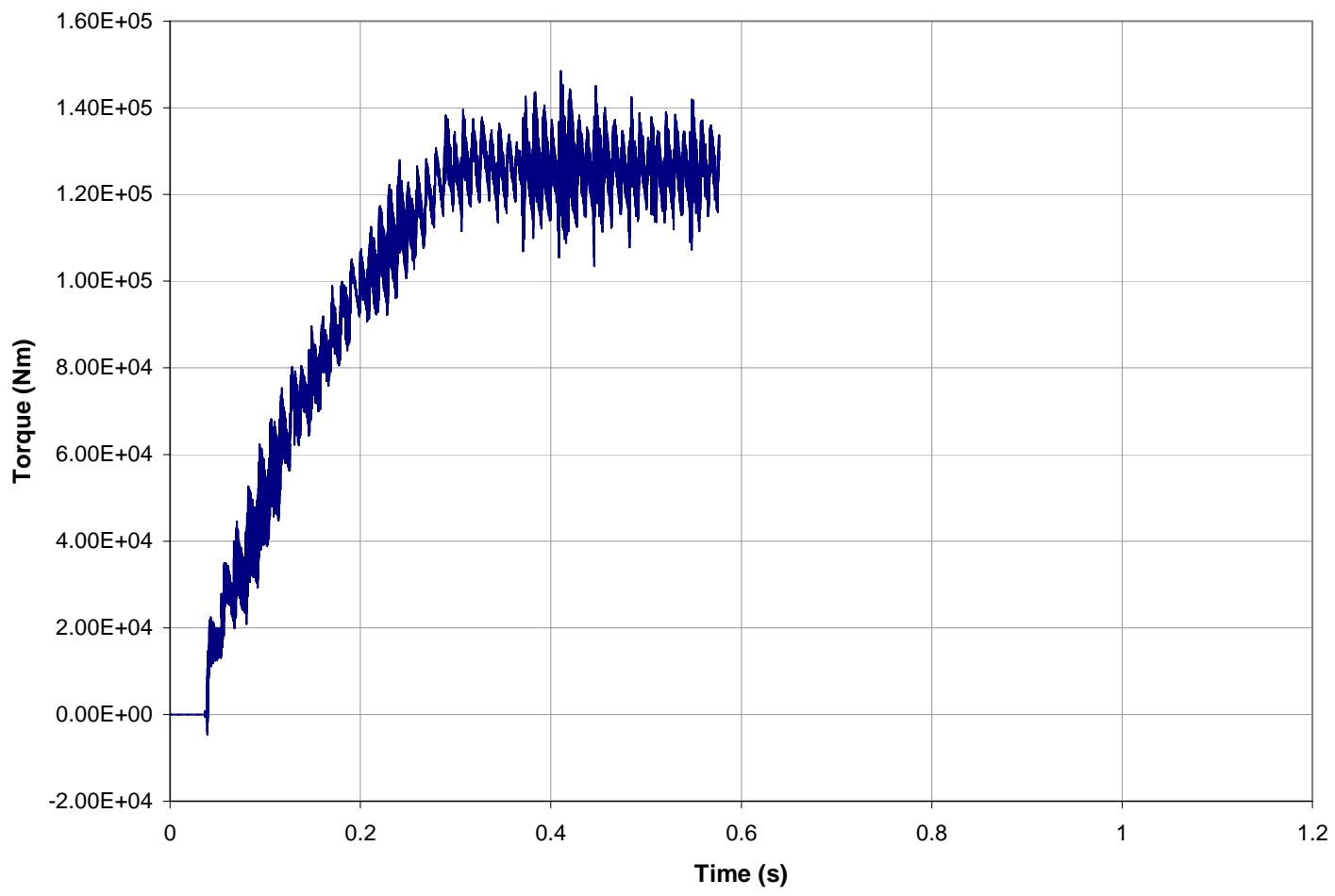

Figure 8 . Torque vs. time in second rolling simulation (element size $\sim 0.023 \mathrm{~m}$ ).

13 


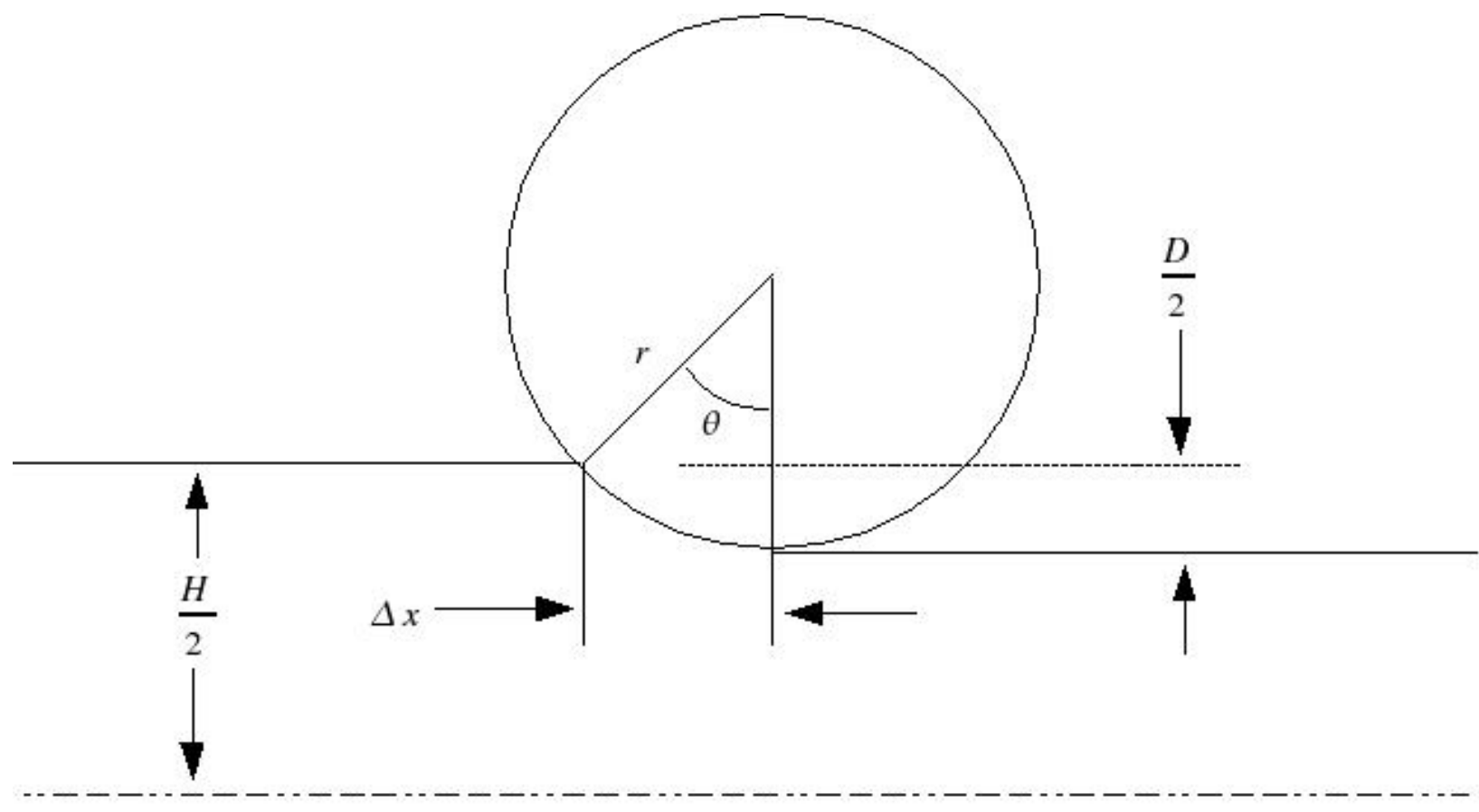

Figure 9. Roll Geometry (not to scale)

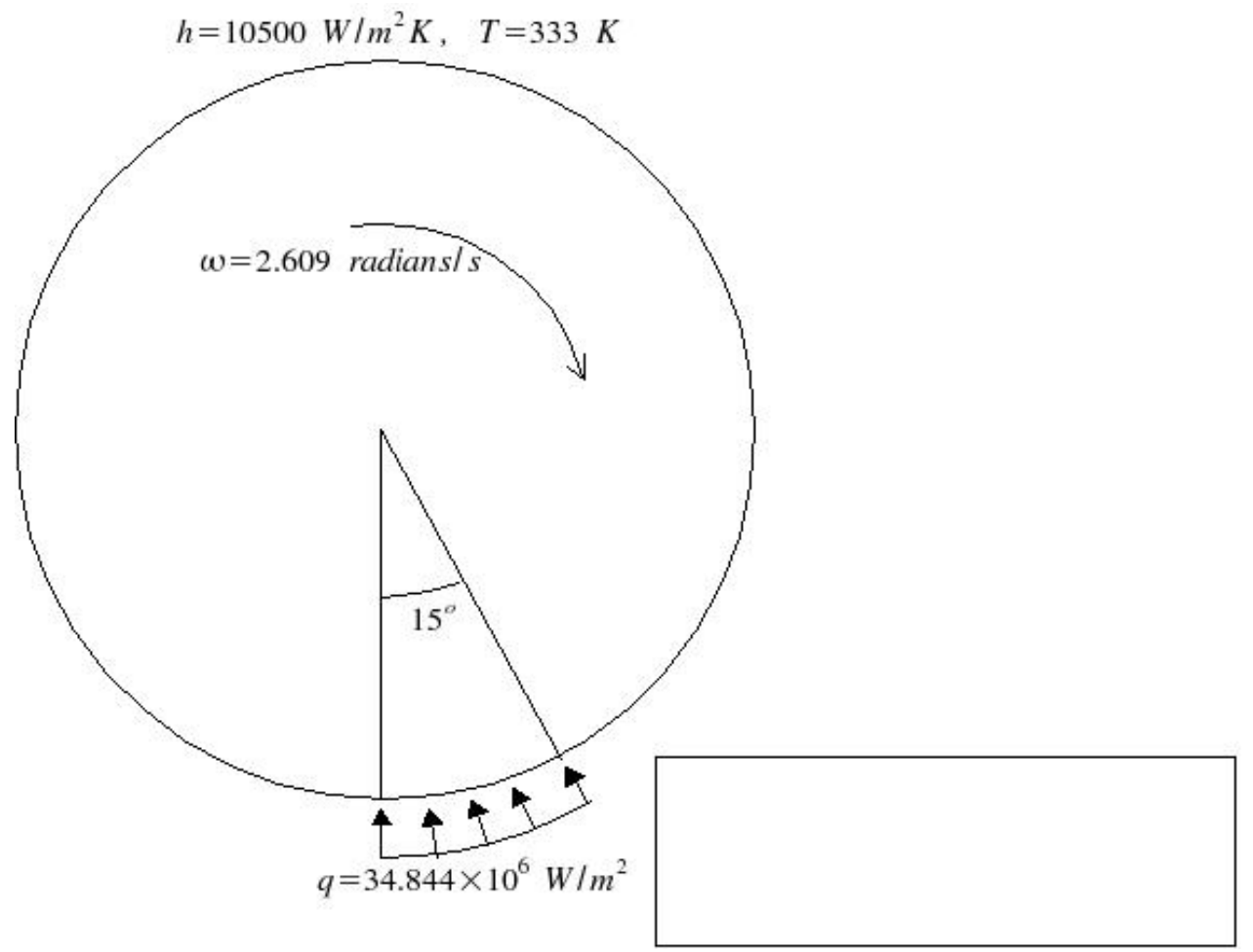

Figure 10. 2-D roll temperature distribution boundary conditions (not to scale). 


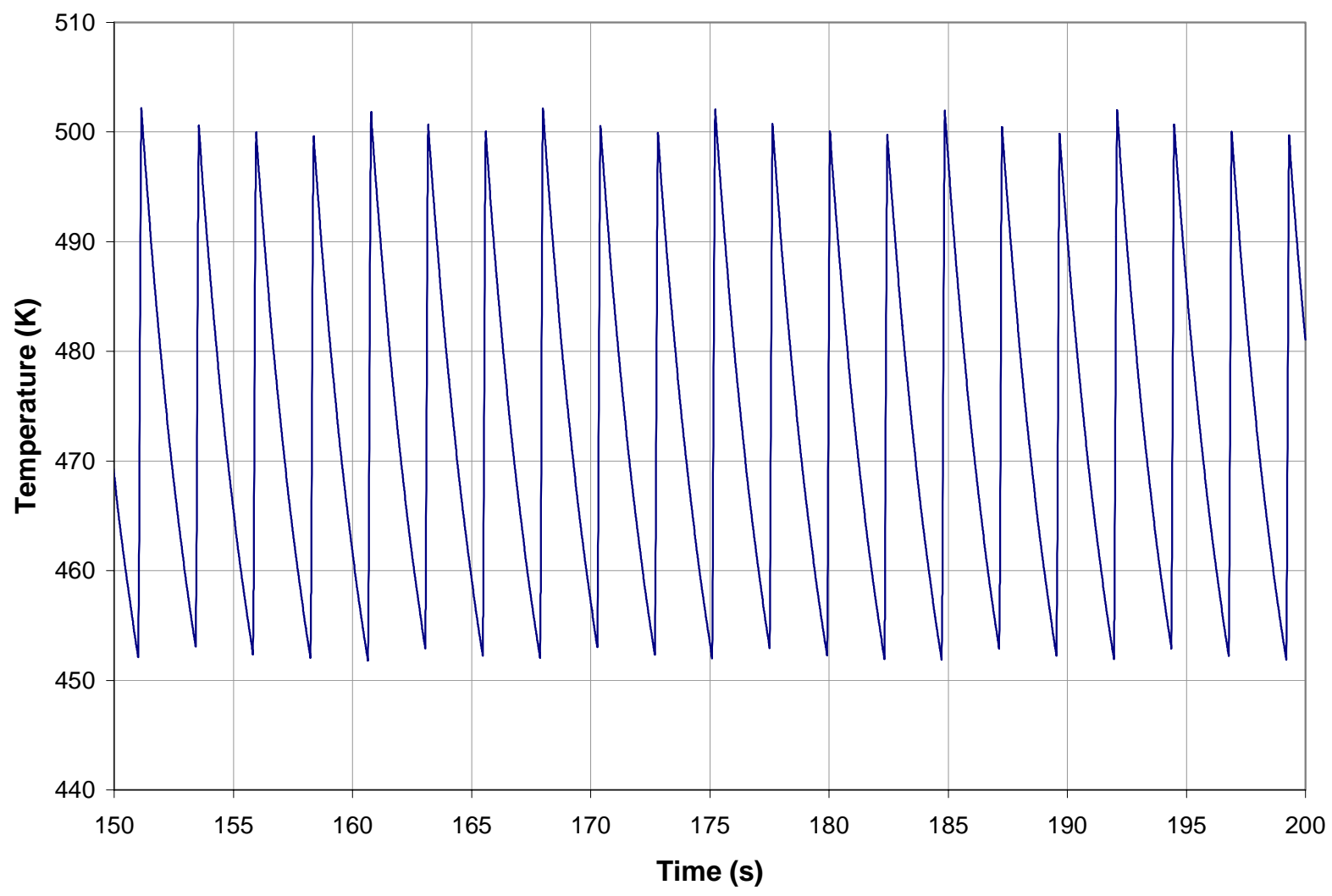

Figure 11. Roll surface element temperature oscillations in 2-D roll heat transfer problem. 


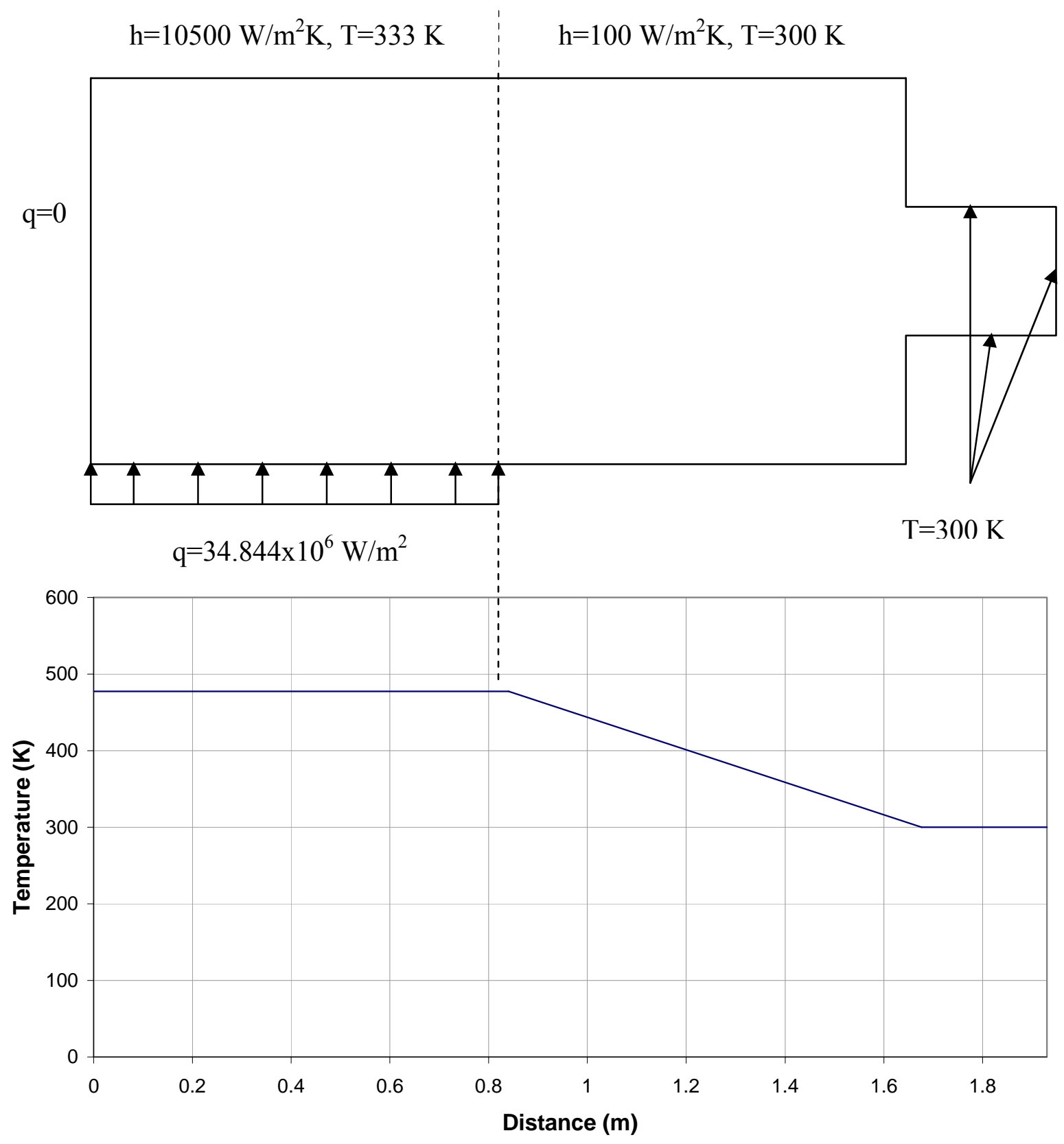

Figure 12. Roll temperature distribution problem boundary conditions and initial temperature distribution (on graph below drawing). 
DB: roll3d_032_200000

Cycle: 200000 Time:200

Mesh

Var: mesh_3d

Pseudocolor

Var: nodet

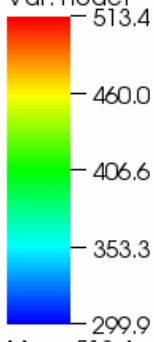

Max: 513.4

Min: 299.9

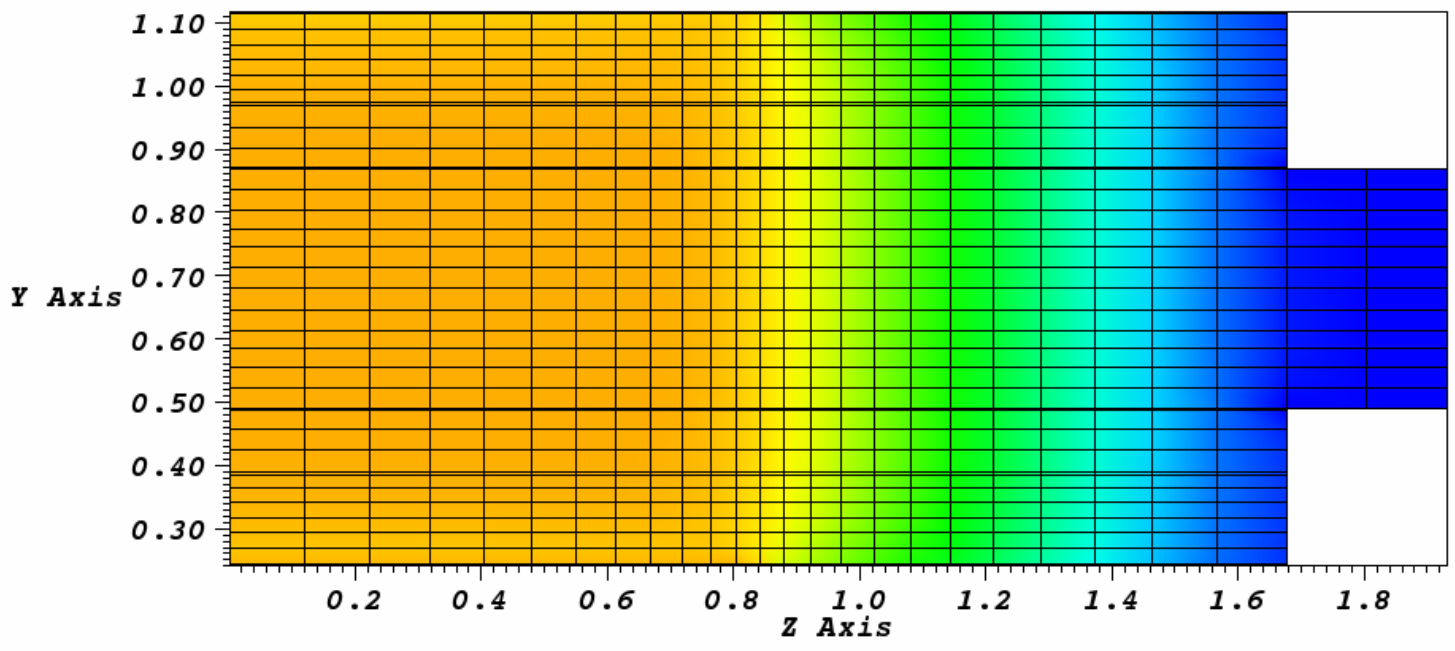

Figure 13. Roll nodal temperature distribution. 


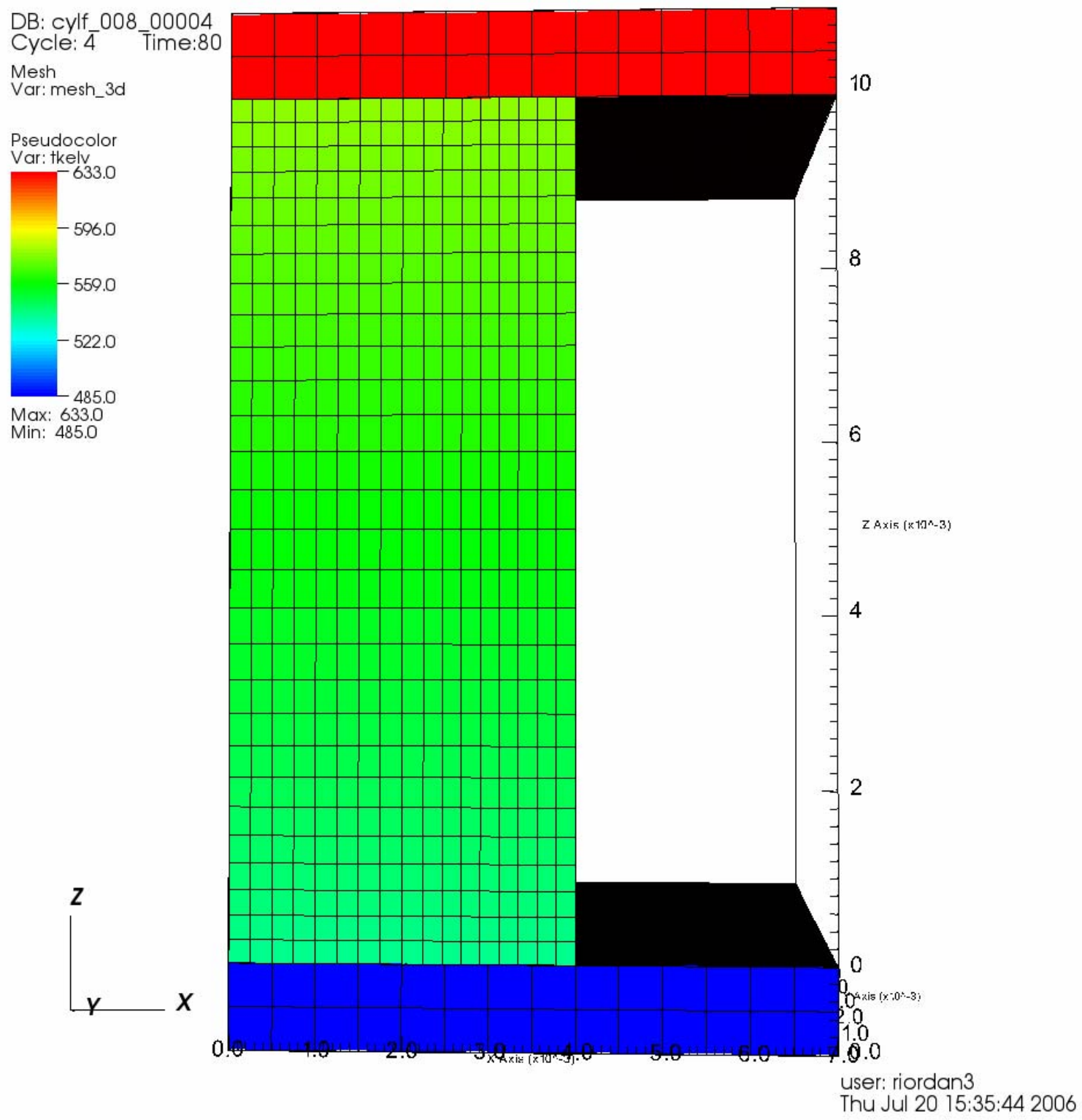

Figure 14. Compression specimen at equilibrium temperature distribution. 


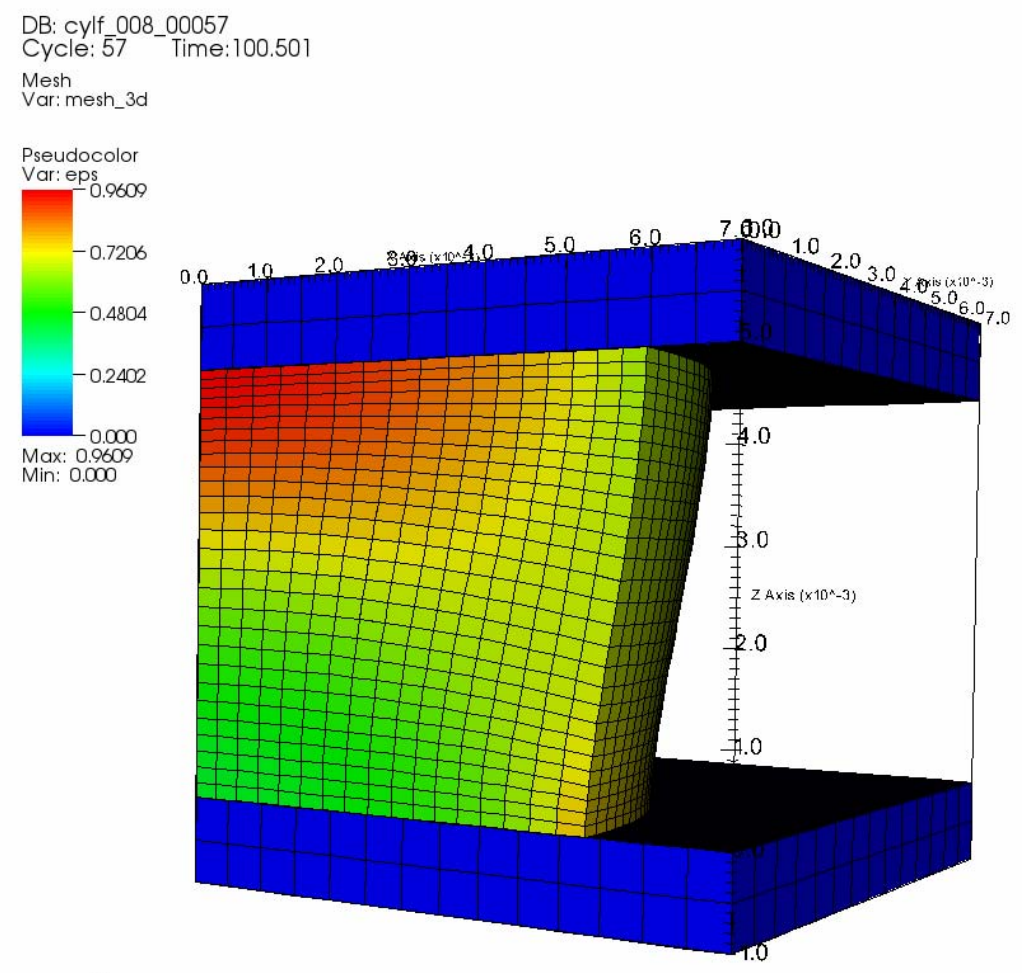

Figure $15^{7}$. Plastic strain distribution at the completion of the implicit simulation.

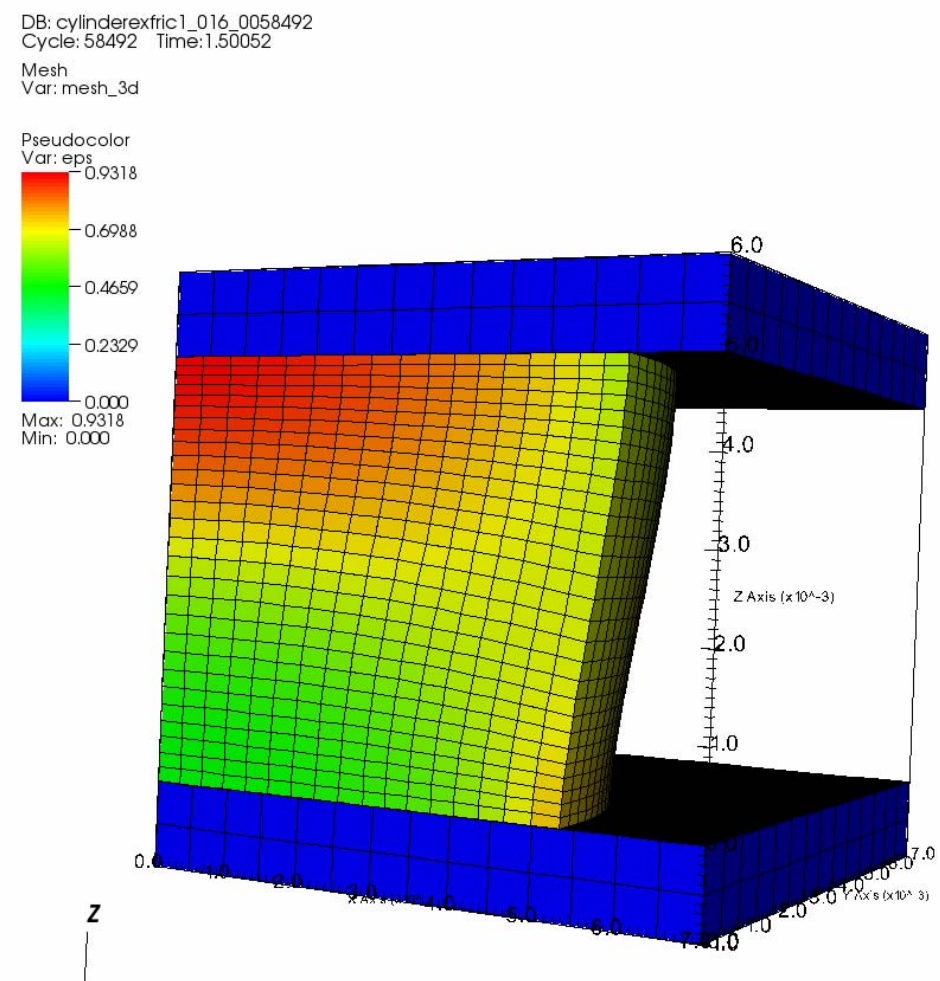

Figure 16. Plastic strain distribution at the completion of the explicit simulation. 


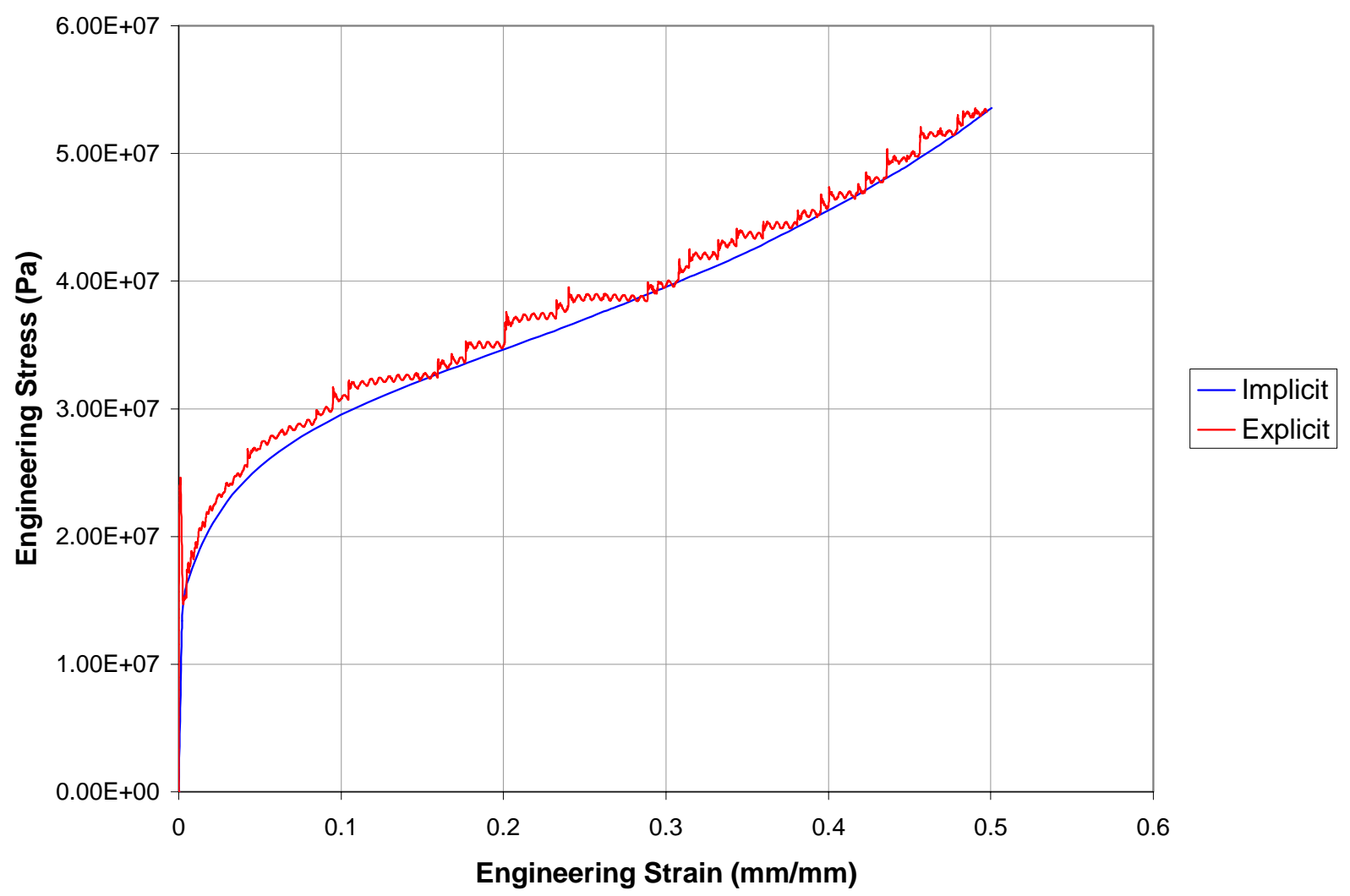

Figure 17. Engineering stress-strain curve for cylindrical compression specimen.

Table 1. Mechanical Threshold Stress parameters [1].

\begin{tabular}{|c|c|c|c|c|c|}
\hline$\mu$ & $\mu_{0}(1-0.00062(T-300))$ & $\mu_{0}$ & $2.5531 \times 10^{4} \mathrm{MPa}$ & $\frac{k}{b^{3}}$ & $0.5899 \mathrm{MPa}$ \\
\hline$\sigma_{a}$ & $10 \mathrm{MPa}$ & $\frac{\hat{\sigma}_{i}}{\mu_{0}}$ & 0.010315 & $\hat{\sigma}_{\varepsilon 0}$ & $1996 \mathrm{MPa}$ \\
\hline$\dot{\varepsilon}_{0 i}$ & $1 \times 10^{7} \mathrm{~s}^{-1}$ & $\dot{\varepsilon}_{0 \varepsilon}$ & $1 \times 10^{7} \mathrm{~s}^{-1}$ & $\dot{\varepsilon}_{0 \varepsilon s}$ & $1 \times 10^{7} \mathrm{~s}^{-1}$ \\
\hline$g_{0 i}$ & 1.196 & $g_{0 \varepsilon}$ & 1.6 & $g_{0 ء s}$ & 0.1058 \\
\hline$p_{i}$ & $1 / 2$ & $p_{\varepsilon}$ & $2 / 3$ & $\theta_{0}$ & $6800 \mathrm{MPa}$ \\
\hline$q_{i}$ & $3 / 2$ & $q_{\varepsilon}$ & 1 & $\kappa$ & 2 \\
\hline
\end{tabular}




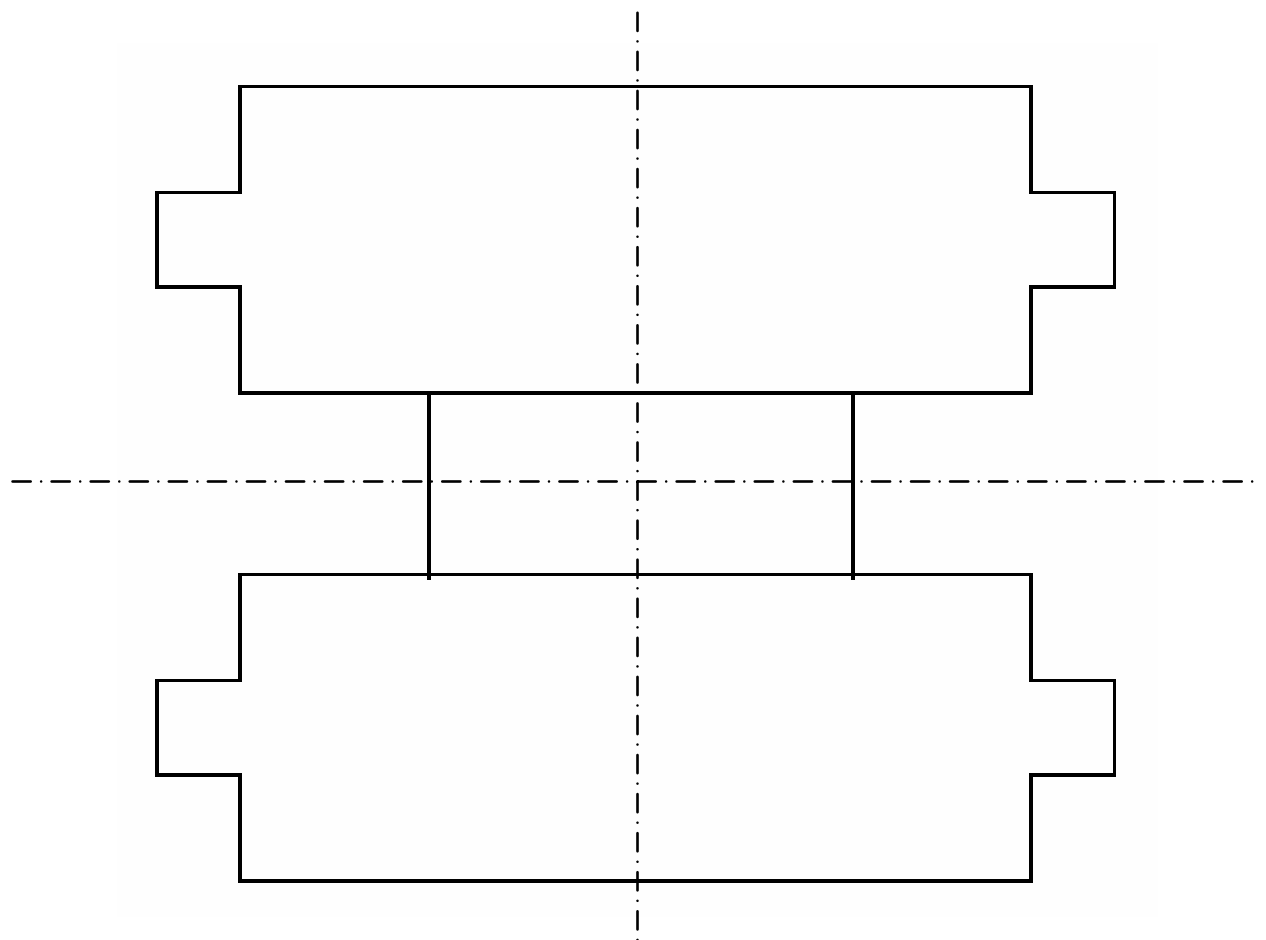

Figure 18. Symmetry planes for three dimensional rolling simulation (not to scale). 